\title{
La COVID-19 y el camino de reconciliación con la muerte
}

La pandemia de coronavirus nos ha sorprendido y atemorizado no solo por la rapidez con la que, habiendo surgido en un lugar alejado de nosotros, se ha apoderado de nuestras vidas, sino sobre todo porque nos ha enfrentado con una muerte posible, rápida y angustiosa, vivida colectivamente a nivel mundial. Una muerte, además, que en la vida de la mayoría de la gente considerábamos lejana, fortuita o incluso esquivable, al menos en un "primer round". Aunque no es automáticamente mortal y la gran mayoría de los que contraen la COVID-19 sobreviven, escuchar noticias de defunciones y ver las gráficas que día a día desgranan muertes sin detenerse, nos hace sentirnos en una especie de lotería mortal en la que hay demasiados primeros premios. El hecho de que la epidemia nos recluya en casa, nos añada mascarillas, variaciones en la vestimenta y nos imponga costumbres que nunca pensamos que fueran indispensables para poder seguir viviendo nos hace sentirnos a la defensiva y obliga a ver la epidemia como una especie de monstruo permanentemente al acecho y que no sabemos cuándo nos puede sorprender. La muerte se hace más presente en nuestras conciencias y por eso mismo es necesario hacer algunas reflexiones al respecto. Y más en esta sociedad de consumo y superficialidad, en la que la muerte, tan normal en la vida humana, trata de ocultarse y olvidarse, como si hubiera que reducirle el peso que tiene dentro de la vida humana. Para comenzar nuestra reflexión, haremos un breve recorrido sobre la percepción de la muerte en diversos momentos de la existencia personal.

\section{El contraste con la idea de la muerte en las diversas etapas de la vida}

Recorrer el contacto con la muerte desde los primeros años infantiles nos ayudará a darnos cuenta de cuánto ha cambiado el concepto en los adultos. Se nos enseñó la muerte como algo lejano, inevitable, pero no peligroso para los niños, salvo en circunstancias especiales. Un coche te podía atropellar en la calle o un rayo en el campo, pero para ambas contingencias había solución: desde el mirar a los lados antes de cruzar, hasta el rezarle a algún santo. Aunque alguna vez viéramos un niño fallecido, la muerte en la infancia resulta generalmente muy lejana y, por tanto, poco problemática.

La adolescencia continúa en un contexto muy semejante y, como joven, la muerte aparece en el horizonte lejano de los deportes de riesgo, de las guerras o de los accidentes. Solo cuando se da la muerte de un conocido más o menos de la misma edad, sea súbita o lenta, pero por una causa natural, el insomnio y el escalofrío se puede apoderar de uno. El cansancio de una noche 
con pesadillas hace, las más de las veces, que el sueño retorne con facilidad un día o dos después, y con él la tranquilidad de la juventud sana. El filósofo Savater decía en una de sus novelas que hasta los 30 años el cuerpo trabaja a favor de la vida. Y que, a partir de esa edad, las cosas cambian y la salud nunca se recupera del todo. En ese sentido, es normal que la muerte no aparezca con fuerza en el horizonte existencial y que ni siquiera la recuperación de la salud se vea como un parche, que solo tapa un desperfecto que nunca se arreglará del todo, como aseveraba Ernst Bloch en su Principio esperanza.

En la experiencia latinoamericana, llegados los 25 o los 30 años, suele darse un cambio, todavía no muy fuerte pero importante. Es la presencia de la muerte evitable. La pobreza, la falta de atención médica, la violencia criminal, o en algunos casos la violencia política, introduce en el contacto masivo con un tipo de muerte que no se mueve en el ámbito de lo inevitable, sino en el campo de la responsabilidad humana. Se trata de muertes sin sentido, brutales muchas veces, o que cortan en flor la belleza de la vida por causas tan simples como infecciones intestinales, broncopulmonares, etc. A veces la falta de vacunas de sarampión se llevaba a los más desnutridos. La desigualdad social lleva a la criminalidad. El individualismo y el consumo generan violencia entre quienes están condenados a no desarrollar sus capacidades y a no poder consumir lo que la propaganda dice que es indispensable para ser feliz. La muerte, entonces, se empodera en las calles.

Se mezclan entonces los sentimientos del sinsentido de determinadas existencias, con la indignación ante un tipo de muerte claramente evitable y evidentemente injusta. El sinsentido encontraba cauce de salida en la protesta, la denuncia y en la confianza de que tras la lucha se consiguieran cambios estructurales que transformaran la realidad en beneficio de los empobrecidos de nuestras tierras. La indignación ante la muerte injusta se desahogaba en la protesta y en la crítica añadiendo la solidaridad, como un valor nacido de la muerte, que terminaba sorprendiendo, e incluso en ocasiones humillando, a los propios asesinos. A veces incluso la huida, peligrosa también y siempre dolorosa, buscaba en la migración mejores horizontes. Pero todavía en esta etapa juvenil, la muerte se visualiza como algo evitable y relegable al largo plazo.

En la madurez, la muerte comienza a ser una parte más consciente de la vida. La exaltación de lo joven en las modas, la cosmética y el cuidado del cuerpo hace que la muerte no sea normalmente tema de conversación. El deseo de retrasar lo más posible la reflexión sobre esa realidad tan propia de la vida se refleja en el esfuerzo por suavizar las palabras que se refieren a la misma. El deterioro del cuerpo se cubre con frases que resaltan lo bien conservado de las personas. Incluso se recurre al maquillaje de difunto, tratando de mantener un recuerdo artificial de la vida. Sin embargo, y más allá de los miedos, la realidad se nos impone con el paso del tiempo, y la persona madura no rehúye la reflexión, muchas veces acompañada de la búsqueda de sentido de la vida en general y de la propia vida en particular. En general, cuanto mayor sentido se le encuentra a la vida, con mayor facilidad se convive con la muerte. Y, al contrario, cuando el sentido de la vida se fija en la 
superficialidad de la misma, en el éxito, la apariencia, el dinero o la fama, la idea de la muerte trata de diluirse en el olvido o en palabras lo más "descafeinadas" que se pueda.

\section{La muerte omnipresente: guerras y represión}

En determinadas situaciones, la muerte se nos impone como tema de reflexión. En El Salvador, las experiencias fuertes de muerte que obligan a reflexionar se dieron en el pasado, especialmente a partir de las masacres. Escuchar y ver el dolor de las mujeres (podemos pensar en Rufina Amaya) y contemplar el ritmo doloroso y dulce a la vez con el que desgranan su viacrucis impactaba profundamente. Es ya un tipo de muerte ante el que hay que pronunciarse. Y que implicaba en su momento la exigencia de comprometerse y asumir algunos riesgos. Para quienes vivieron esos momentos en su juventud, y especialmente si se rebelaban contra ese tipo de brutalidad criminal, la muerte dejaba de ser algo lejano y comenzaba a convertirse en una realidad cada vez más cercana, permanente e incluso asumida.

Aunque el compromiso consistiera únicamente en moverse en el campo de la denuncia, criticando determinados modos de actuar y de pensar característicos de la deshumanizada barbarie que se había instalado entonces en Centroamérica, la vida comenzaba a experimentar cambios. Se buscaban mecanismos de solidaridad y denuncia. Y a partir de ellos se comenzaba a sentir que la muerte evitable estaba cada vez más cercana del que era solidario, y no era ya un problema de los otros. La muerte comenzaba ya a sentirse como un problema personal. A la indignación y al compromiso se sumaba una cierta porción de miedo. Morir era una posibilidad cercana aun sin el terror que puede dar una epidemia que no se sabe bien a quién matará y a quién dejará vivir. El miedo era distinto porque, cuando hay una causa, los sueños heroicos distraen del vacío de la muerte.

La muerte de los amigos impacta. Y más la de aquellos que tienen los mismos ideales. En las guerras civiles, la vorágine de los conflictos nos envuelve en la irracionalidad y con frecuencia ese ver lo irracional que es el matar, al tiempo que nos preocupa, nos acaba haciendo pensar que si actuamos racionalmente podremos sobrevivir. El mismo día que mataron al P. Ellacuría, aparecía en España una entrevista con él en el periódico catalán l'Avui. El titular en la primera página era la respuesta de Ellacuría a la pregunta de si había posibilidad de que lo asesinaran. El texto en primera plana decía: "Sería tan irracional que me mataran". En aquellos tiempos la justicia y la libertad, incluso el trabajo por la paz, no hacían más que multiplicar el riesgo, pues dominaba la irracionalidad del asesino. Para quienes vivimos en El Salvador, la masacre de los seis jesuitas y sus dos colaboradoras fue una verdadera inmersión en el fenómeno de la muerte. Pero también una inmersión en la solidaridad. La sobreabundancia de la muerte, desde la que ocurría con demasiada frecuencia en las calles y en las cárceles sin que aparecieran en los periódicos, hasta la de los jesuitas, como parte permanente y siempre presente de la guerra, hacía que los que quedábamos vivos nos considerásemos hermanos, más allá de los contextos y las razones de la brutalidad. Hermanos ante el terror, dispuestos a 
ayudarse y a salir juntos con vida y en defensa de la vida. Y precisamente esa hermandad se convirtió en una extraordinaria fuerza para superar el miedo a ese tipo de muerte causada por el odio al semejante.

El caso de los jesuitas tuvo esa dimensión de tragedia que termina, casi inmediatamente, desarrollando hermandad en la lucha contra la muerte. Por eso mismo, a pesar del dolor, fue más fácil de integrar. Se trataba de un hecho sorprendente, en muchos aspectos aterrorizante por lo cercano y por lo irracional. Pero al fin y al cabo asumible tanto por la propia fe cristiana de quienes aspirábamos a ser constructores de paz, como por la misión arriesgada que los jesuitas habían asumido de construir la paz con justicia. Pero, sobre todo, porque el efecto de creación de hermandad fue impresionante. Desde niños de escuelas y colegios, junto con grupos laicales de parroquias, hasta personalidades del mundo de la política, de la cultura y de la Iglesia, los mensajes de solidaridad no dejaban de llegar. El mismo día que los mataron, eran tantos los mensajes de solidaridad, que los jesuitas pudieron sentir que era cierta la frase del salmo 98 que se repetía durante la misa que estaban celebrando: "Los confines de la tierra han contemplado la victoria de nuestro Dios". A la masiva solidaridad, se sumaron los Congresos de Estados Unidos y España, así como el Parlamento de Inglaterra, que enviaron delegaciones de diputados para investigar lo sucedido. La información veraz, solidaria y comprometida del periodismo internacional, contrarrestando las mentiras del Gobierno salvadoreño y sus intentos de encubrir el crimen, fue constante.

Lo que se hizo en el campo de la justicia y la constancia en las actividades de reparación y conocimiento de la verdad, se pudo hacer, en torno al caso jesuitas, gracias a esa corriente de hermandad que generó su muerte. Ellos habían luchado contra la muerte sistemática de los más pobres y sencillos del país y finalmente se unieron a ellos en el mismo trágico destino. La solidaridad internacional revivía con ellos el recuerdo de los que como ellos habían sido asesinados. Incluso la posterior muerte de quienes arriesgaron su vida en tiempo de la guerra, ya muertos en tiempo de paz y por causas naturales, como por ejemplo el fallecimiento de María Julia Hernández, aunque se lamentara profundamente, se veía como un tránsito hacia esa dimensión de la vida verdadera de quienes habían luchado en favor de los demás y de sus derechos, sin miedo a la muerte.

Hoy, con la COVID-19, la situación es diferente. Se trata de una especie de lotería mortal que amenaza a todos, cuya causa se vincula tanto con descuidos personales como con procesos civilizatorios en los que la despreocupación por el medio ambiente, la falta de prevención y la comercialización de la medicina que impide una investigación más sistemática continúan generando un mundo vulnerable y en riesgo, especialmente para los más pobres. Si la muerte en solidaridad con las víctimas de una historia violenta e injusta tiene siempre sentido, la muerte por la COVID-19 termina sintiéndose como absurda. Es mucho más difícil para la persona normal luchar contra las causas de este tipo de muerte, siempre con una base estructural tanto política como económica. Y ni siquiera se nos ofrece como suficiente el consuelo de la sabiduría popular, 
que nos dice que todos tenemos que morir. Porque este tipo de epidemia se hubiera podido prevenir y nadie debería morir por su causa.

La causa principal de muerte en el mundo son los problemas cardiocirculatorios. La COVID-19 no llegará a matar tantas personas durante el 2020 como mataron los problemas cardiocirculatorios en 2017. Pero mientras la muerte por problemas cardíacos se mira como natural, pues se trata de un órgano muscular que tarde o temprano se deteriora y falla, la COVID-19 aparece de repente como un enemigo nuevo que aumenta el número de muertes y que pesa como una amenaza constante. Las mismas medidas para evitarlo se convierten para muchos en un tiempo inseguro de espera que angustia, que reduce defensas y que multiplica otras dolencias, aunque solo sea porque, centrado todo el sistema de salud en la pandemia, se desatienden otras enfermedades crónicas como la diabetes, la hipertensión o la insuficiencia renal, tan extendida en El Salvador. La COVID-19 adelanta aleatoriamente la fecha de la muerte para muchos e impide nuestra idea generalizada de muerte tranquila, rodeados de familiares y personas queridas. Con el entierro en solitario o en fosas comunes, estipulado por la legislación de emergencia, ni siquiera queda el recurso del velorio, ese sistema tan latinoamericano de ir aceptando la pérdida del ser querido desde la solidaridad de quienes lo conocieron y apreciaron.

\section{El mundo construido por los pequeños}

Aunque el mundo en el que vivimos, diverso, interconectado social, cultural, política y económicamente, y al mismo tiempo complejo, necesita liderazgos creativos e inteligentes, no son los liderazgos los que los que construyen el mundo en cuanto vivible y soportable. Al final son los valores de la gente sencilla que entiende lo que es la solidaridad, el servicio, el agradecimiento y la capacidad de sacrificarse generosamente por el débil los que mantienen al mundo con esperanza y lo hacen vivible para los seres humanos. Y son precisamente los sencillos y los débiles los que demuestran muchas veces la eficacia de esos valores, los que resisten en ellos y los que despiertan esa misma capacidad de servir y arriesgar la vida por el bien de otros.

No es difícil pensar que este mundo se hubiera ya terminado si dependiera para existir de la memoria contada por los privilegiados y triunfadores, siempre plagada de guerras y depredación de la naturaleza, que con tanta frecuencia se convierten en la historia oficial de los países. Recordamos las guerras, las victorias, los reyes, la revoluciones, las traiciones, las supuestas heroicidades de los vencedores y las felonías casi siempre aumentadas de los vencidos. Al menos así suelen contar las cosas los historiadores cautivados por el nacionalismo y el culto al poder. Solo de vez en cuando, en medio del canto en favor de los poderosos, surge con una fuerza irresistible el testimonio de alguien que se convirtió en recipiente de tanto bien y amor acumulado por los pequeños que rompió los moldes de las historias oficiales. Jesús de Nazaret como signo del amor absoluto convertido en amor al prójimo es para nosotros, los cristianos, la muestra más poderosa del triunfo de los descartados por la historia. Francisco de Asís, Gandhi, Martin Luther King, Mons. Romero y muchos otros más reviven la figura del crucificado o de sus valores de servicio y amor generoso. 
Y aunque los poderosos tratan de asimilar la historia de estas personas a sus propios intereses, estas figuras terminan siempre trascendiendo todo interés egoísta y convirtiéndose en fuerza crítica y solidaria.

Pero no solo permanecen estimulantes en la memoria las grandes figuras históricas que dieron testimonio de generosidad y amor. En el recuerdo personal de mucha gente, permanecen como fuente de energía generosa amigos, $e$ incluso seres anónimos, que echaron una mano en el caminar. Los judíos sobrevivientes de la brutalidad nazi recuerdan como "justos" a quienes les ayudaron a esconderse o a sobrevivir, aun a riesgo de ser asesinados. El riesgo asumido por amor al prójimo termina siendo siempre más fuerte y duradero, en el largo plazo, que la barbarie de un dictador presentada como el bien máximo desde el poder absoluto. Estas personas que salvan al prójimo dan más sentido a la historia y a la vida concreta de los seres humanos que cualquiera de los grandes y poderosos de la historia oficial, aunque les llamemos próceres, y disfrutemos adornando nuestra plazas y calles con sus nombres y sus estatuas. San Agustín, hablando de la paz, decía que no puede haber ninguna guerra sin algún tipo de paz "porque la guerra supone siempre hombres o naturalezas humanas que la mantienen, y ninguna naturaleza puede existir sin alguna especie de paz". Y son esos, los que preservan la paz en medio de las guerras, los que acaban dándole sentido a la existencia en momentos en los que parece que la humanidad ha perdido el sentido.

En efecto, de los pequeños salvadores de vidas, aunque se pierdan sus nombres con la muerte de quienes fueron auxiliados, queda el amor acumulado y multiplicado en la vida de muchos. La ternura materna no solo es instinto, sino cultura acumulada, lo mismo que la fidelidad a los amigos, el amor a la tierra y a lo que a cada uno le identifica con el desprendimiento y la capacidad de hacer el bien. Hay una cultura del amor que se acumula. Y dentro de esa cultura del amor tiene sentido incluso la más leve esperanza generada desde el prójimo, así como el más pequeño signo de solidaridad. Los campesinos que dan comida a un guerrillero o a un soldado hambriento porque les daba lástima ver aquella juventud sufriente, mostraban un sentido de humanidad muy superior al de quienes gestionaban la guerra. Los que esconden perseguidos por poderes violentos, alimentan migrantes y peregrinos, atienden y se solidarizan con los refugiados, señalan mejor el camino de la humanidad que aquellos que no se tientan la conciencia cuando en sus guerras y en sus políticas hablan de daños colaterales al referirse a víctimas inocentes.

Incluso las víctimas inocentes y sin voz regeneran la vida. Los 130 y tantos niños de El Mozote, con su edad promedio de seis años, asesinados a sangre fría en un solo lugar en medio de una masacre de mil campesinos, son parte de esa historia del amor. Frustrada, cortada en capullo más que en flor, esa tierna niñez ensangrentada estaba ahí porque sus padres amaban la tierra que cultivaban y no la quisieron abandonar. Estaban ahí porque sus familias confiaban en la bondad humana y no podían pensar en la matanza que se avecinaba. Estaban ahí simple y sencillamente porque sus padres eran buenos, incapaces de prever tanto mal. Estaban ahí por ser hijos de la bondad y ser ellos mismos, en su propia esencia e inocencia, buenos. Como los Santos 
Inocentes, los niños de El Mozote fueron asesinados por el odio contra todo intento de que la justicia floreciera entre los pobres. Cuando en El Salvador se investigaba la barbarie ocurrida en El Mozote, consolaba y animaba el hecho de que uno de los miembros de la Comisión de la Verdad, Thomas Buergenthal, era uno de los sobrevivientes más jóvenes del campo de exterminio de Auschwitz. Encontrarse con Rufina Amaya y escucharla era comenzar a contemplar el fracaso de los verdugos y percibir el inicio del triunfo de la dignidad de las víctimas.

Los pequeños no pasan. Simplemente se acumula su bondad en esos sentimientos de humanidad crecientes que van forzando a que el mundo no se autodestruya, a que los corazones no se cierren, a que las luchas por la paz y la dignidad humana no desaparezcan, a que la dignidad humana siga floreciendo de mil modos diferentes, a pesar de llevar una lucha desigual con la mentira, la propaganda y con las múltiple maneras de inducirnos a pensar que la división entre superiores e inferiores, entre dignos e indignos, entre ricos $y$ pobres, es una realidad natural.

\section{El valor de las víctimas}

Y entramos así en otra de las intuiciones que reconcilian con la muerte. Se trata del valor de las víctimas. Un mundo incapaz de rescatar y honrar a las víctimas de su propia historia jamás podrá ser feliz. Porque la felicidad no puede construirse sobre el sacrificio y el dolor olvidado de tantos que fueron el presupuesto de la felicidad de otros en el presente. Olvidarlos haría que la felicidad del futuro fuera tan egoísta que necesariamente entraría en contradicción con la posible felicidad de otros. Las víctimas, por el contrario, con sus valores, con su resistencia, con su generosidad, nos enseñan a indignarnos frente al mal, a ser compasivos con el que sufre, a tener hambre y sed de justicia frente a la injusticia, a celebrar su recuerdo integrándolo en la historia en favor del bien, y a emprender el camino de una entrega y de un servicio sin el que es imposible la felicidad.

Tal vez se nos podrá decir que el valor de las víctimas solo se pone al descubierto cuando estas son conocidas, están en posiciones de prestigio, o se desvela posteriormente su heroicidad. Pero que las víctimas del coronavirus, del cáncer, del maltrato intrafamiliar solo expresan el mal con el que la humanidad tiene que cargar. Y aunque es cierto que el mal continúa operando en muy diversas circunstancias, lo cierto es que el que sufre nos pone siempre en la alternativa de servir o de abandonar la tarea de crecer en humanidad. Además, la persona expuesta a un sufrimiento evitable o inevitable, que encara su sufrir desde el amor a la vida y sus valores, expresa lo mejor de la dignidad humana y se convierte en testimonio de humanidad. La resiliencia de los ancianos, los más propensos a morir en la pandemia, la resistencia de médicos y enfermeras, la misma lucha por la vida de quienes contraen la COVID-19, que envían palabras de ánimo a sus familiares desde el aislamiento hospitalario, son parte del amor la vida y del esfuerzo humano de construir la convivencia

sobre la solidaridad. Incluso cuando llega la muerte, quien ha luchado, ha sido 
solidario, ha confiado en quienes quieren ayudarle, pasa a ser recordado como parte integrante de la bondad y la dignidad humana.

Aunque largas, estas consideraciones sobre la muerte y la pandemia nos llevan a hablar de la necesidad de enfrentar la muerte con dignidad. No queremos que nadie muera en el desarrollo de esta pandemia, pero sabemos que mucha gente sufrirá mientras la enfermedad perdure, y algunos morirán. Frente a ello debemos asumir una actitud semejante a la de las luchas contra todo tipo de violencia: resistencia activa contra toda clase de egoísmo, división $\mathrm{u}$ odio creadores de víctimas. Porque, efectivamente, hay mucho de desprecio de la dignidad humana cuando una pandemia se da porque no se investiga lo que no da dinero. La realidad nos llama a posicionarnos ante una nueva amenaza a nuestra humanidad con una doble actitud: la actitud de amor a la vida, que lucha por la vida frente a toda injusticia y frente a toda enfermedad hasta el último momento, y la actitud de serenidad del que sabe que el afrontar los problemas, incluso la muerte, en lucha con el mal y en paz con el prójimo, es parte de esa tarea a la que estamos llamados todos a la hora de multiplicar el amor en esta tierra.

La primera tarea, pues, es la de luchar en favor de la salud en todo tipo de instancia, nacional o internacional. El mundo actual tiene la capacidad de vencer las enfermedades causadas por diferentes patógenos, incluidos los virus. Pero si estas enfermedades afectan prioritariamente a los pobres, la inversión en la investigación disminuye drásticamente. Todos conocemos unos derechos de patentes de medicinas que se imponen como prioritarios sobre la salud humana y que solo se superan tras largas luchas. La pandemia de gripe causada por el virus H1N1 de 2009 fue tachada de falsa crisis pandémica en beneficio de la industria farmacéutica. Muchos de los expertos estratégicos de la Organización Mundial de la Salud (OMS) recibían dinero de las grandes empresas farmacéuticas. Algunos estudios calculaban que la declaración del H1N1 como pandemia (que no mostraba más virulencia que la gripe común estacional) generó una ganancia de 10,000 millones de dólares a las empresas farmacéuticas. No es difícil entender que la OMS, en las actuales circunstancias, fuera lenta en la declaración de pandemia, más allá de la discutida falta de transparencia china. Enfrentar y oponerse a la tendencia actual a considerar la salud como un negocio es una primera tarea ética ante nuestra propia realidad y, por supuesto, frente a cualquier amenaza a la salud dentro y fuera de nuestro país. La pandemia de la COVID-19, mientras ha traído pérdidas de trabajo y pobreza para millones de personas, ha sido escenario también del enriquecimiento rápido de algunos multimillonarios. Según el Institute for Policy Studies, la fortuna de Jeff Bezos aumentó en el mes de abril en 25,000 millones de dólares, una cantidad ligeramente superior al PIB de Honduras. Cuando el dolor de los pobres es más evidente, la desigualdad debe mitigarse, disminuir y no aumentar.

Pero ¿qué decir de países donde la desigualdad es tradicionalmente dramática? En países como El Salvador, según un estudio de 2008 del Programa de las Naciones Unidas para el Desarrollo (PNUD), el gasto anual en salud de las instituciones públicas que atendían al 99 \% de la población era equivalente al 
gasto privado en salud que atendía a un poco menos del $1 \%$ de la población. La brutalidad de la desigualdad en este campo básico de la dignidad humana, que no ha cambiado demasiado desde entonces, indica con demasiada claridad el desinterés por la salud. El mismo sistema público de salud, con sus instituciones de diversa calidad establecida a partir del ingreso individual, nos muestra con evidencia el menosprecio de los más pobres y el desprecio hacia la salud como derecho común y universal. Hoy la COVID-19 ha tenido la virtualidad de impulsar una respuesta común e igualitaria para todos (o casi todos). ¿Regresaremos después de esta crisis a un sistema de salud público de baja calidad que además discrimina, ofende a los más pobres y es causa de la pésima preparación con la que nos ha sorprendido la pandemia actual? Luchar en todos los ambientes posibles en favor de una salud eficiente, digna y que trata a todos con la misma diligencia y esfuerzo es imprescindible si queremos salir de la crisis actual sin caer en otra peor.

Y a la dinámica de lucha en favor de una salud pública de calidad debe acompañarle la memoria de la generosidad de tantas personas que han arriesgado vidas y futuro sirviendo y posibilitando que la vida continúe, aun en medio de las dificultades. La generosidad de algunos debe convertirse en esperanza para todos. El mañana será mejor si somos capaces de contemplar con alegría los esfuerzos de médicos o enfermeras que multiplican su actividad de servicio o se han contagiado tratando de curar; si admiramos a los cuidadores de ancianos y enfermos que a pesar de las dificultades de transporte han continuado viajando y posibilitando la vida de los más vulnerables; si respetamos como servidores básicos a las cajeras de los supermercados, a los empleados de las farmacias, a los motoristas que transportan medicinas o alimentación, a los comerciantes en informalidad, todos ellos trabajando para todos nosotros a cambio de un salario generalmente demasiado pequeño; $y$ si nos solidarizamos también con los periodistas que tratan de informarnos en una situación con frecuencia opaca. Aunque no hayamos mencionado a todos los que sirven y ayudan, podemos decir que tenemos demasiada gente buena en época de crisis como para que la olvidemos tras la pandemia, no retomemos su ejemplo y no construyamos una sociedad que les ofrezca una mayor justicia social.

Solo entonces podremos llegar a la muerte, más allá de los normales miedos, con la satisfacción de haber vivido. La muerte honrosa y ejemplar se encuentra no solo en los campos de batalla o en la muerte heroica de los mártires, sino también en esa batalla del espíritu que trata de confiar en la vida, en el amor y en el bien hasta el último momento de la existencia. Toda existencia humana llega en algún momento a su fin. Pero el final será siempre más sereno si sabemos que hemos amado y luchado en favor de la vida. Karl Rahner, uno de los teólogos más importantes de la segunda mitad del siglo $\mathrm{XX}$, decía que el espíritu humano, lo que llamamos normalmente el alma, tras la muerte se vuelve "pancósmico". En otras palabras, continúa influyendo en la vida universal desde el bien que contribuyó a crear. Y aunque no pierda la muerte su dimensión trágica y dolorosa, el peso del bien realizado continúa mejorando a la humanidad. Mejora que disminuye en la medida en que no 
hayamos sabido enfrentar adecuadamente este tipo de enfermedades previsibles, curables y, al menos reducibles en su letalidad, como la COVID-19.

Los verdugos antiguos, y todavía algunos de sus herederos actuales, creían en la muerte como un factor de solución de los conflictos humanos. También con la pandemia de la COVID-19 surgieron algunos líderes políticos que veían que la muerte de unos cuantos podía ser solución para la pandemia. Pensaban que el contagio, aunque algunos murieran, terminaba por dar inmunidad a la mayoría. La "inmunidad del rebaño", se la llamaba, con esa tendencia casi hegeliana de ver a las víctimas, ancianos, pobres y personas vulnerables, como florecillas aplastadas por el carro de la historia. Otros no le dieron la importancia a la crisis de salud hasta demasiado tarde. La irresponsabilidad y la insensibilidad humana, mezclada con la prepotencia de quienes saben que el poder político y económico protege mejor contra la muerte, mostraron las debilidades del mundo poco solidario en que vivimos. Solo el grito de la gente consciente y decente, y solo la muerte digna de quienes enfrentan la muerte recordada desde el servicio y la generosidad, convertida en memoria generadora de justicia, obligarán a cambiar el presente injusto y darán sentido al dolor de la pandemia. Lo demás, la palabrería, los gritos en las redes, las propagandas políticas, quedarán convertidos, citando un verso del gran poeta peruano César Vallejo, en "coágulos de sombra oliendo a olvido".

\section{La lucha por la vida y la dignidad de la muerte}

Y hemos entrado así en la dimensión que nos lleva al encuentro de la muerte con dignidad, y que nos ofrece incluso la posibilidad de llamar a la muerte, como san Francisco de Asís, "hermana muerte", después de haber llamado hermanos a todos los seres humanos y hermanas a todas las criaturas. En efecto, luchar en favor de la vida prepara para la muerte. Para quienes vivimos en el tercer mundo es mucho más familiar la lucha en favor de la vida amenazada por egoísmos institucionalizados y por estructuras sociales francamente injustas, así como por la violencia que estos generan. Pero es también evidente que todo esfuerzo por acrecentar las parcelas verdes de solidaridad en este mundo en epidemia y crisis permanente de salud se transforma en verdadera lucha por la vida.

Hoy, cuando las amenazas a la vida ya existentes se acrecientan con la pandemia de la COVID-19, luchar por la vida adquiere una dimensión de emergencia. Solo desde esa lucha solidaria y generosa, podremos decir como Pablo de Tarso al final de su vida que hemos crecido en humanidad: "he consumado la carrera, he conservado la fe, solo me espera recibir la corona de la justicia que me dará el Señor" (2 Tim 4, 7-8). Esta es la lucha por la vida, la lucha real de la existencia, la gran batalla de la historia que nos permitirá vivir, como decía un antiguo capitán, "sin que la muerte al ojo estorbo sea". Porque la muerte, aunque es desposesión contundente de lo que se tiene, no anula lo que se es.

A todos nos preocupa la muerte. La de los seres queridos y, por supuesto, la propia. Todas las religiones se han ocupado del tema, porque el miedo a 
lo desconocido despierta siempre preguntas. En general, todas las formas religiosas que surgieron en torno a lo que Karl Jaspers llamaba la "era axial" vincula tanto la muerte como el más allá de ella con el modo de vivir la vida. En general, el concepto de lo que llamamos lo humano tiene una enorme deuda con la concepción humanista de las grandes religiones. En la novela Águila de blasón, de Valle Inclán, la madre de un joven asesinado, noble ella, consentidora de los caprichos y desmanes de su heredero y con una religión más puesta en rezos que en vida, termina diciendo frente al cadáver de su hijo: "Qué tarde he comprendido que antes de ser bueno es necesario ser humano".

Es precisamente esa humanidad, que nos permite ver la bondad en la gente sencilla y solidarizarnos con todas las personas que son privadas de los legítimos derechos de humanidad, la que también nos permite acercarnos a la muerte con la conciencia tranquila y la seguridad de que nos acercamos a la maduración final de nuestro aporte a la historia del amor. Y aunque nunca lleguemos a vencer del todo los terrores de esa noche oscura definitiva, podremos llegar a ella con esperanza y con una profunda confianza en la vida, que es más fuerte que nuestra propia muerte personal. La muerte nunca fue un cierre ni una frontera para los corazones y los espíritus generosos, porque saben que lo que no puedan ellos terminar en esta vida lo seguirán otros desde la misma esperanza y el mismo amor. La esperanza cristiana de que al final de los tiempos Dios será "todo en todas las cosas" (1 Cor 15, 28) tiene su base en que Jesús, el Cristo, ha superado la muerte, mostrándonos en su amor concreto a los más pobres de su tiempo el sentido de la vida y el camino y la verdad de la plenitud humana. Ante la COVID-19, y ante todo el desastre socioeconómico y cultural que engendra una pandemia, lo que nos prepara para saber vivir e incluso saber morir es el esfuerzo por proteger al prójimo, la solidaridad con los débiles y el esfuerzo por cambiar las estructuras socioeconómicas que posibilitan que en las catástrofes mueran muchos más los pobres y la población de bajos recursos. Solo de esa manera el cristiano podrá repetir con Pablo de Tarso que vivir es necesario para servir y que la muerte se convierte en ganancia cuando la vida ha sido solidaria y generosa. 